\title{
Role of Prostaglandins in the Vasodilator Effect of the Aqueous Extract from Artemisia annua Plant in Streptozotocin-induced Diabetic Rats
}

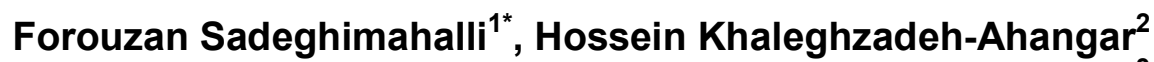 \\ and Tourandokht Baluchnejadmojarad ${ }^{3}$ \\ ${ }^{1}$ Department of Physiology, School of Medicine, Mazandaran University of Medical Sciences, \\ Sari, Iran. \\ ${ }^{2}$ Department of Physiology, School of Medicine, Babol University of Medical Sciences, Babol, Iran. \\ ${ }^{3}$ Department of Physiology, School of Medicine, Iran University of Medical Sciences, Tehran, Iran.
}

Authors' contributions

This work was carried out in collaboration among all authors. Author FS designed the study, performed the statistical analysis and wrote the first draft of the manuscript. Author TB managed the analyses of the study. Author HKA managed the literature searches and wrote the protocol. All authors read and approved the final manuscript.

Article Information

DOI: 10.9734/ARRB/2019/v31i630069

Editor(s):

(1) Dr. J. David Puett, Professor, Department of Biochemistry and Molecular Biology, University of Georgia, Athens, USA.

(2) Dr. George Perry, Dean and Professor of Biology, University of Texas at San Antonio, USA.

Reviewers:

(1) Dr. Mahendran Sekar, Universiti Kuala Lumpur, Malaysia.

(2) E. Siva Rami Reddy, Tantia University, India.

(3) Dr. Godstime Isi Irabor, Saba University School of Medicine, Netherlands. Complete Peer review History: http://www.sdiarticle3.com/review-history/49243

Original Research Article

Received 09 March 2019

Accepted 23 May 2019

Published 01 June 2019

\section{ABSTRACT}

Aims: One of the most important causes of mortality is vascular complications resulting from diabetes mellitus. Herbal medicines are commonly used for the treatment of cardiovascular conditions in diabetes. Artemisia annua ( $A$. annua) as a medicinal plant has vasculature protective effects in diabetic rats. In the present study, the role of prostaglandins in the vasodilator effect of $A$. annua aqueous extract in diabetic rats has been studied.

Study Design: This animal study was conducted on diabetic rats. Aqueous extract of Artemisia annua was used for diabetic rats. Then, isolated thoracic aortic rings were exposed to indomethacin and after exposure, the contractile responses were measured. 
Methodology: The studied animals were male Wistar rats $(n=36)$ which were randomly divided into intact, untreated-diabetic, and $A$. annua aqueous extract treated-diabetic groups. For the induction of diabetes, streptozotocin was intraperitoneally (i.p.) administered $(60 \mathrm{mg} / \mathrm{kg}$ ). A. annua extracttreated group received i.p. $100 \mathrm{mg} / \mathrm{kg}$ of extract for one month. After one month, the dose contractile response of isolated aortic rings to phenylephrine (doses of $10^{-9}-10^{-4} \mathrm{~mol} / \mathrm{L}$ ) in the absence and presence of indomethacin as a prostaglandins inhibitor was determined using isolated tissue setup.

Results: Comparison of contractile responses before and after adding indomethacin in treated extract diabetic rats, showed that contractile responses of aorta ring with and without endothelium after adding indomethacin significantly increased at all concentrations of phenylephrine $(P<0.05-$ $\mathrm{P}<0.0001)$ while indomethacin in diabetic rats did not effect on contractile response.

Conclusions: Since the vasodilator effect of the aqueous extract of $A$. annua with a concentration of $100 \mathrm{mg} / \mathrm{kg}$ of body weight was pronounced even after endothelium removal, it can be claimed that the vasodilator effects of the extract are related to inhibition of prostaglandin generation both indirectly and directly.

Keywords: Artemisia annua; vasodilator effect; prostaglandins; diabetic rats.

\section{INTRODUCTION}

Prevalence of diabetes is enhancing globally. Vascular complications in diabetes arise from chronic hyperglycemia which causes mortality in diabetic patients $[1,2]$. Some of the vascular complications of diabetes mellitus including the increase in thickness of capillary basement membranes [3], the decrease in microvessels density [4], the vascular endothelial cell degeneration [5], the changes in vascular endothelial responses [6], the decrease in endothelial capacity for production and release of nitric oxide (NO) in response to free radicals released in the cyclooxygenase pathway [7].Nowadays, the use of medicinal plants containing flavonoids has been considered due to their therapeutic and pharmacological properties for the treatment and prevention of cardiovascular complications of diabetes [8,9]. The management of pathological changes in diabetic vascular has been continuing challenge for many decades. Current strategies for drug development are based on prevention of vascular complications. Nowadays, the usage of herbal medicines with their bioactive components provide a promising approach for the debarment and treatment of diabetic vascular complications $[1,10]$. Among the medicinal plants, the plant genus Artemisia consists of 1500 diverse species with several healing properties [11]; one of them is Artemisia annua found in Southeast Asia and north of Iran [12]. The Artemisia plants are rich in bioactive substances that have various effects such as cardiovascular effects. The Artemisia plants can be considered as antihypertensive substance and preventing the vascular damages [13.14-16]. The Artemisia extracts derivatives in acute and sub-chronic exposure, lead to decreasing heart rate and systolic blood pressure $[17,18]$. Another species called $A$. herba-alba, caused smooth muscle relaxation in rabbits [19]. The chemicals isolated from the Artemisia plant were able to inhibit the enzyme monoamine oxidase, which plays a key role in the metabolism of norepinephrine (NE) and epinephrine (EP), leads to vasodilation [20]. Helal et al. had a study on the anti-diabetic effect of this plant. Their results showed that the oral use of the aqueous extract of $A$. annua was able to reduce blood glucose and lipid profiles in alloxan-induced diabetic animals [21]. Moreover, sub-chronic administration of $A$. annua aqueous extract reduced plasma glucose in animals and also was able to prevent the aortic contractile response to the alpha-adrenergic agonist [22]. In addition, in our previous study, we investigated the role of $\mathrm{NO}$ and intracellular calcium sources in the effect of vasorelaxation of $A$. annua aqueous extract on isolated aortic responsiveness to phenylephrine in diabetic rats. The results illustrated that the vasodilator effect of this plant was endothelium-dependent through the production or release of $\mathrm{NO}$, as well as inhibiting the release of calcium from intracellular sources [12]. So far a few studies have been conducted on the mechanisms of medicinal plants. Considering the majority of therapeutic aspects of herbal medicines in chronic disorders such as vascular complications of diabetes mellitus and considering the anti-diabetic effect of $A$. annua aqueous extract, studying its possible mechanisms of vasodilatation would be important. It seems that the cyclooxygenase pathway is a candidate for the vasodilatation effect of this plant as another mechanism. Therefore, in the present study, the role of indomethacin as a cyclooxygenase inhibitor, in 
the vasodilator effect of aqueous extract of $A$. annua in diabetic rats was investigated.

\section{MATERIALS AND METHODS}

\subsection{Animals}

Male Albino Wistar rats, weighing 220-250 g were obtained from the Pasteur Institute of Iran (Tehran) and were housed in an air-conditioned colony room on a light/dark cycle at $22 \pm 3^{\circ} \mathrm{C}$ and supplied with a standard pellet diet and tap water. All groups of rats were maintained under standard housing conditions for a period of 4 weeks with free access to food and water. The procedures involving the animals' use and care were approved by the ethics committee of Iran University of Medical Sciences, Tehran, Iran, and conducted in conformity with the National Institutes of Heals Guidelines.

\subsection{Drugs}

Streptozotocin (STZ), Phenylephrine hydrochloride and indomethacin were purchased from Sigma (St. Louis, Mo, USA). All other chemicals were from Merck (Germany).

\subsection{Preparation of Aqueous Artemisia Extract}

The aerial parts of Artemisia annua (Dermaneh) were collected from Babolsar, a city of Mazandaran province, north of Iran, during the late spring season. The plant was taxonomically identified by botanists in the Department of Biology (Tehran University, Iran). The powder of air-dried herb $(100 \mathrm{~g})$ was added to one liter of boiled distilled water and kept the temperature at $60^{\circ} \mathrm{C}$ for $15 \mathrm{~min}$. Then, it was filtered three times through the filter paper. The obtained liquid was dried at $37^{\circ} \mathrm{C}$ until a concentrated residue $(62 \%$ $\mathrm{w} / \mathrm{w}$ ) was obtained. This stock extract was maintained at $-20^{\circ} \mathrm{C}$ until being used and it was diluted with normal saline to make the desired concentration [22].

\subsection{Experimental Procedures}

In the experiment, totally three groups including eight rats in each group were used: Group A) Vehicle-treated intact rats received daily saline (0.5 ml/day) for four weeks. Group B) Vehicletreated diabetic rats received daily saline as a drug solvent (0.5 ml/day) for four weeks. C) Extract-treated diabetic rats received daily Artemisia extract $(100 \mathrm{mg} / \mathrm{kg} / 0.5 \mathrm{ml}$ saline) for four weeks.
For diabetes induction, STZ was dissolved freshly in cold normal saline. Then, a single i.p. injection of $60 \mathrm{mg} / \mathrm{kg}$ dose of it was performed. After $72 \mathrm{~h}$ blood glucose concentrations were measured. The animals which had glucose levels more than $250 \mathrm{mg} / \mathrm{dl}$ were considered as diabetic rats.

Body weight and serum glucose of all rats were determined before and 3 weeks after i.p. injection of saline or Artemisia extract (100 mg/kg) [22].

\subsection{Preparation of Aortic Rings}

The applied procedure has been described before [22]. Briefly, four weeks after the experiment, the animals were anesthetized with diethyl ether and thoracic aortas were excised and trimmed free from adhering fat and connective tissues. Then, the aortic tissues were placed in a Petri dish filled with Krebs solution of the following composition (in $\mathrm{mmol} / \mathrm{L}$ ): $\mathrm{NaCl}$, $118.5 ; \mathrm{KCl}, 4.74 ; \mathrm{CaCl}_{2}, 2.5 ; \mathrm{MgSO}_{4}, 1.18$; $\mathrm{KH}_{2} \mathrm{PO}_{4}, 1.18 ; \mathrm{NaHCO}_{3}, 24.9$ and glucose, 10.0.

The dissected aorta was cut transversely into rings of $3-4 \mathrm{~mm}$ in length. Rings with or without endothelium were mounted in an organ bath of $50 \mathrm{ml}$ capacity filled with Krebs solution that was kept at $37^{\circ} \mathrm{C}$ and continuously bubbled with a $95 \% \mathrm{O}_{2}$ and $5 \% \mathrm{CO}_{2}$ gas mixture. Following the equilibrium period, dose-response curves were obtained with phenylephrine. Phenylephrine was added in a cumulative manner $\left(10^{-9}-10^{-4} \mathrm{~mol} / \mathrm{L}\right)$ until a maximal response was achieved. After the addition of each dose, a plateau response was obtained before the addition of a subsequent dose. Half an hour after recording the contraction response of aortic rings to phenylephrine $\left(10^{-9}\right.$ $10^{-4} \mathrm{~mol} / \mathrm{L}$ ) and washing the rings with and without endothelium, 10 $\mu \mathrm{mol}$ of indomethacin (as a cyclooxygenase inhibitor) was added to the organ bath. Then, again the contraction response of aortic rings to phenylephrine was recorded. The contraction response of the aortic rings was digitized online on the computer using isometric transducers (F-60 myograph, Narco-Biosystem) and signals were stored for offline analysis.

\subsection{Data Analysis}

The contractile responses of aortic rings to phenylephrine with or without endothelium were expressed as grams of tension per milligram of tissue. All values were expressed as means \pm SEM. Statistical significance was indicated by $\mathrm{P}<0.05$, which was obtained from multiple t-tests. 


\section{RESULTS}

\subsection{Body Weight and Serum glucose}

Comparing the results of weight and serum glucose from the rats before and after the 4 weeks test indicated that the weight of untreated diabetic rats decreased one month after diabetes induction $(\mathrm{P}<0.001)$ but in animals receiving $A$. annua aqueous extract, the weight of animals increased significantly $(P<0.0001)$. On the other hand, comparison of serum glucose in untreated diabetic animals and diabetic rats treated with aqueous extract of this plant showed that 4 weeks of treatment of animals with $A$. annua extract significantly reduced the serum glucose level $(P<0.0001)$ (Table 1).

\subsection{The Role of Prostaglandins in Contractile Response of Aorta in Vehicle-treated Rats}

To investigate the role of prostaglandins in the contractile response of aortic rings with endothelium and without endothelium, cumulative dose-response curve to phenylephrine at the concentrations of $10^{-9} \mathrm{M}$ to $10^{-4} \mathrm{M}$ from aortic rings before and after adding indomethacin was recorded. The results showed that in the intact animals receiving physiological saline for one month, after adding indomethacin to the organ bath, the contractile response of the aortic rings with endothelium in the concentrations of phenylephrine from $10^{-7} \mathrm{M}$ to $10^{-4} \mathrm{M}$ was significantly increased $(\mathrm{P}<0.01)$ (Fig. 1A). Comparing the contractile response of aortic rings without endothelium before and after adding indomethacin to the organ bath in intact animals receiving the physiological saline for one month showed no significant difference in any of the phenylephrine concentrations (Fig. 1B).

\subsection{The Role of Prostaglandins in Aortic Contractile Responses in Vehicle- treated Diabetic Rats}

The results of the cumulative effect of phenylephrine on contractile response of the aortic rings in untreated diabetic rats receiving saline for one month indicated that before and after adding indomethacin to the organ bath the contractile response of the aortic rings with and without endothelium had no significant difference at any concentrations of phenylephrine (Fig. 2A and $\mathrm{B}$ ).

\subsection{The Role of Prostaglandins in the Aortic Contractile Response in Extract-treated Diabetic Rats}

Comparison of the contractile response of aortic rings in treated diabetic rats receiving i.p. injection of $100 \mathrm{mg} / \mathrm{kg}$ of $A$. annua aqueous extract per day for one month illustrated that the contractile response in the aortic rings with endothelium at concentrations of phenylephrine from $10^{-7} \mathrm{M}$ to $10^{-4} \mathrm{M}$ had significantly increased $(\mathrm{P}<0.05-\mathrm{P}<0.0001)$ (Fig. 3A). Additionally, in diabetic rats treated with aqueous extract of $A$. annua, after adding indomethacin to the organ bath, there was a significant increase in the contractile response of aortic rings without endothelium $(P<0.01-P<0.001)$ (Fig. 3B).

\section{DISCUSSION}

The present study results indicated that the treatment of diabetic rats with the aqueous extract of $A$. annua could normalize the plasma glucose and lost body weight which is based on the healing properties of this plant for diabetes mellitus. The results of Helal et al study wereaccording to our results [21]. In the present study, indomethacin in aortic rings with endothelium and not in without endothelium ones in vehicle-treated rats increased the contractile response to phenylephrine, while it had no effect on contractile responses of aortic rings with or without endothelium in diabetic rats. However, in A. annua treated diabetic animals, the contractile response to indomethacin has increased in both with aortic rings and without endothelium ones. Cyclooxygenase pathway products are synthesized in vessels smooth muscles and endothelial cells from arachidonic acid [23]. Thromboxane $A_{2}$ released from the vessels endothelial is a vasoconstrictor [24] and prostacyclin (PGI2) is a vasodilator metabolite produced in this pathway from the vessels endothelial and their smooth muscle [23]. Adrenergic agonists in the smooth muscle of the vessels with G-protein stimulation can activate the pathway of cyclooxygenase and cause biosynthesis of vasodilators or vasoconstrictors which depends on the type of the vessels $[25,26]$. According to the results of other studies, it has been confirmed that endothelium-derived 
Table 1. Body weight and plasma glucose in intact rats, untreated rats, and treated diabetic ones. Data expressed as means $\pm S E M, n=8$. VT: Vehicle-treated, VD: Vehicle-treated diabetic, ED: Extract-treated diabetic

\begin{tabular}{llll}
\hline Groups & Serum glucose $\mathbf{( m g / d l})$ & \multicolumn{2}{c}{ Body weight $\mathbf{( g )}$} \\
\cline { 3 - 4 } & & Before experiment & After experiment \\
\hline VT & $96.89 \pm 1$ & $210.55 \pm 5.48$ & $230.18 \pm 4.25$ \\
VD & $560 \pm 40.20$ & $227.9 \pm 9.33$ & $+178 \pm 2.53$ \\
ED & $102.01 \pm 3.82$ & $220 \pm 4.56$ & ${ }_{2} 260.2 \pm 8.3$ \\
\hline
\end{tabular}

$\$ P<0.0001$ comparisons of body weight $(g)$ between $E D$ and $V D$ group, $+P<0.001$ comparisons of body weight (g) before and after the experiment in VD group, * $P<0.0001$ comparisons of glucose serum between $E D$ and VD groups
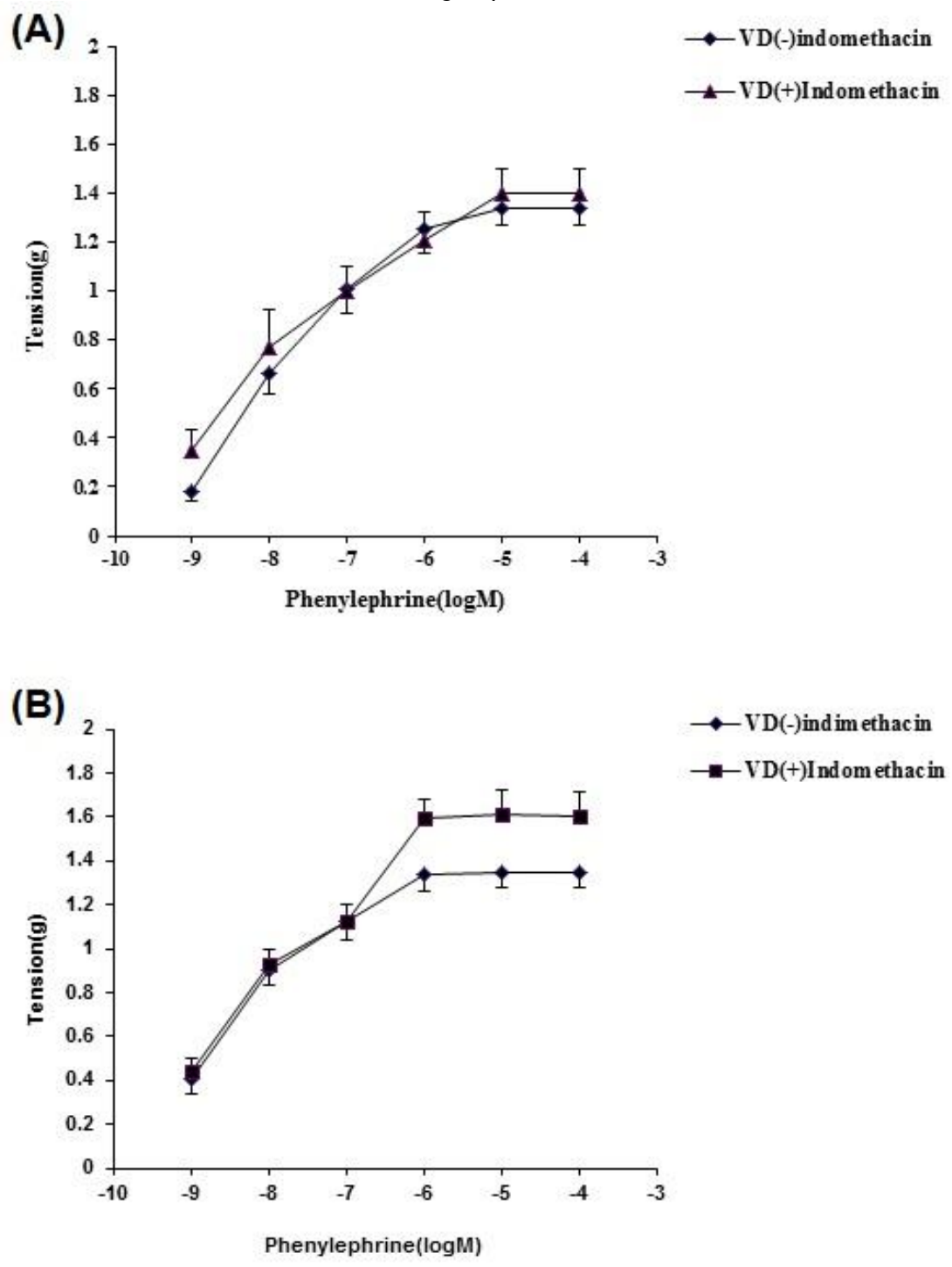

Fig. 1. Cumulative concentration-response curve for phenylephrine in the aorta with endothelium (A) and without endothelium (B) in the presence and absence of indomethacin from VT (vehicle-treated) group in intact rats which received the saline for 4 weeks

Data are expressed as means \pm SEM, $n=8,{ }^{*} P<0.05$ difference between before and after indomethacin at the same group 


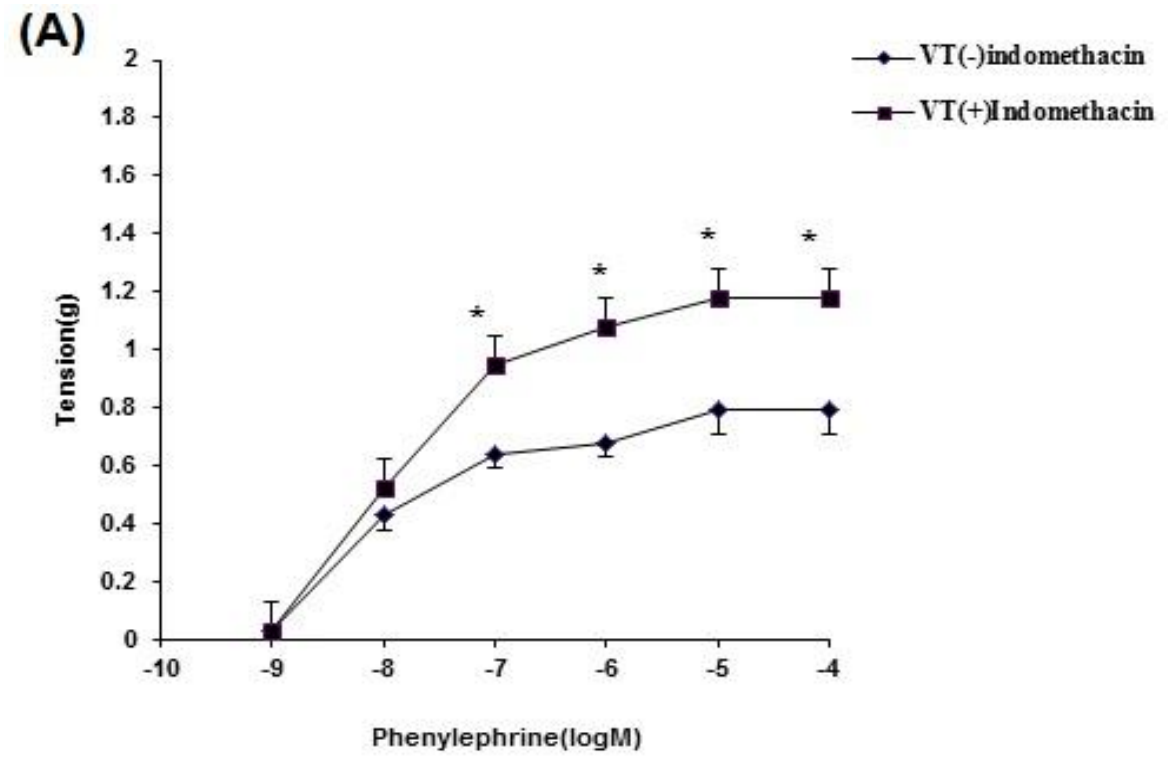

(B)

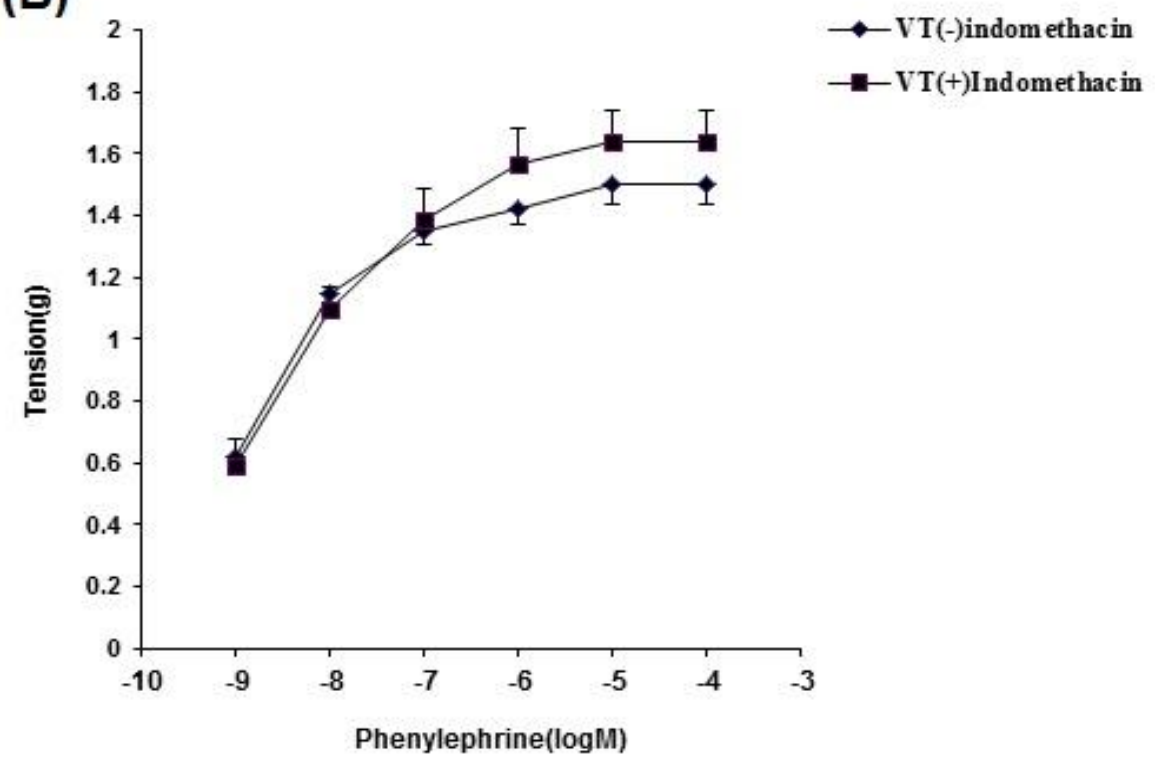

Fig. 2. Cumulative concentration-response curve for phenylephrine in the aorta with endothelium (A) and without endothelium (B), in the presence and absence of indomethacin from VD (vehicle-treated Diabetic) group in diabetic rats which received the saline for 4 weeks

Data are expressed as means \pm SEM, $n=8$

factors have effects on the contractile response of adrenoceptors [26]. Based on the results obtained in this study, indomethacin did not change the contractile response of aortic rings to phenylephrine in diabetic animals. It is well known that gradually with the progression of diabetes; the vessels lose their normal function and undergo the changes which are partly related to the vascular capacity for the synthesis and release of vasoactive prostanoids [27]. In the diabetic vessels, the balance of PGI2/TXA2 is failed and the synthesis of TXA2 is increased 
due to increased release of arachidonic acid from platelet phospholipids. Hyperlipidemia in diabetes also increases the production of TXA2 from vascular endothelium, which ultimately causes hypertension, atherosclerosis, and platelet aggregation [28]. The synthesis and release of PGI2 (prostacyclin) from the arachidonic acid was decreased in the aorta of diabetic animals $[29,30]$. Reducing prostacyclin synthase activity due to $\mathrm{H}_{2} \mathrm{O}_{2}$ produced from endothelium [31] and reducing the available substrate are other causes of decreased prostacyclin synthesis in the diabetic vessels [29]. Based on the present study, it can be mentioned that the aqueous extract of $A$. annua acts through the cyclooxygenase pathway by increasing vasodilators from both the vessels' smooth muscle and also their endothelium.

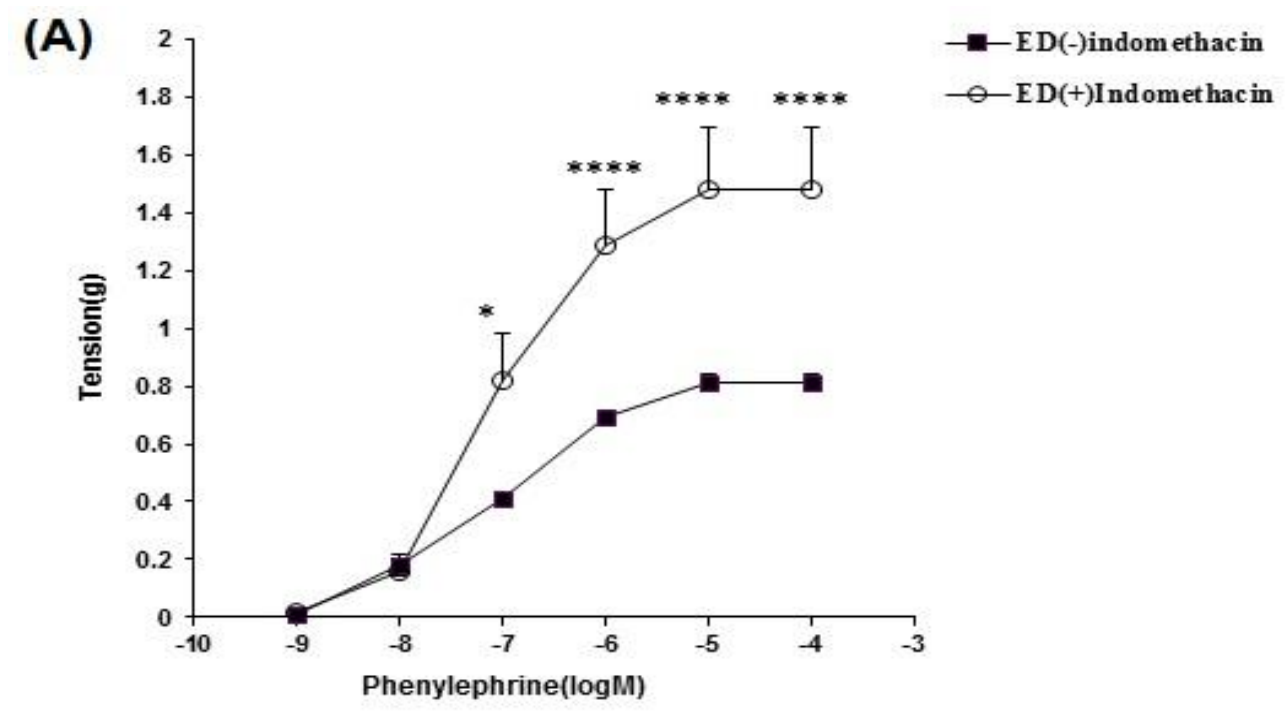

(B)

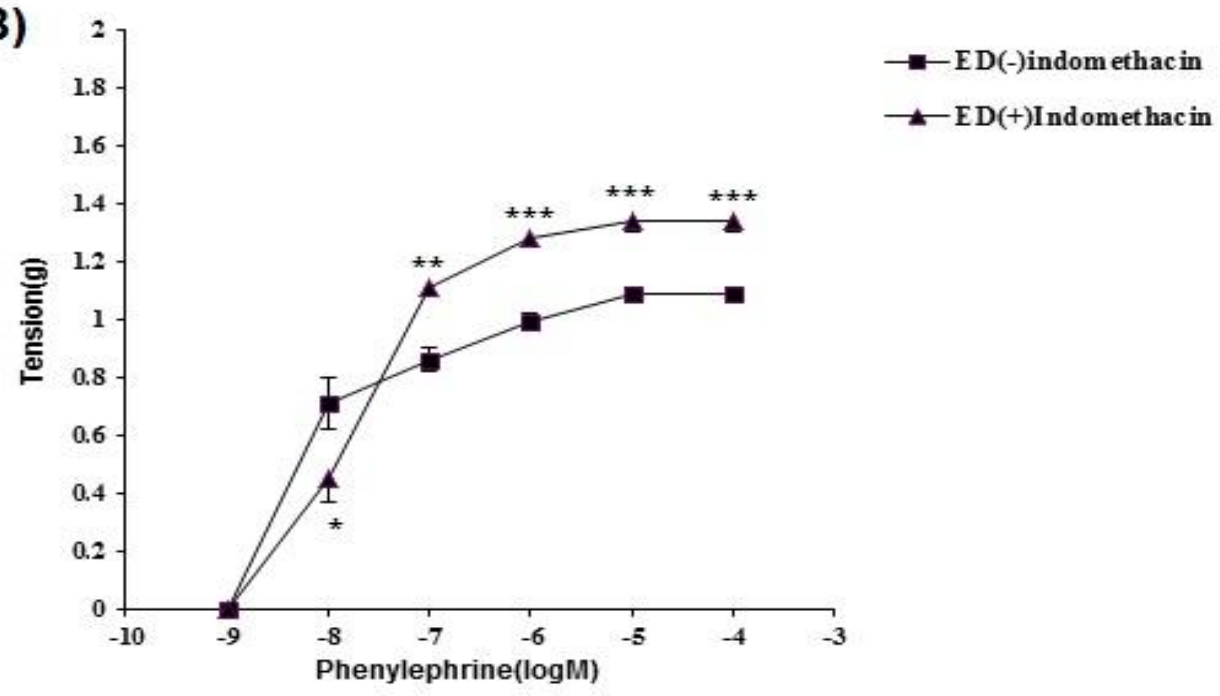

Fig. 3. Cumulative concentration-response curve for phenylephrine in the aorta with endothelium (A) and without endothelium (B) in the presence and absence of indomethacin from ED (Extract -treated diabetic) group in diabetic rats which received $100 \mathrm{mg} / \mathrm{kg}$ dose of Artemisia annua extract for $\mathbf{4}$ weeks

Data are expressed as means \pm SEM, $n=8,{ }^{*} P<0.05,{ }^{* *} P<0.01,{ }^{* * *} P<0.001$, and ${ }^{* * * *} P<0.0001$, the difference between before and after indomethacin at the same group 
In our previous study, the vasodilatation mechanisms of this plant extract were investigated in isolated thoracic aorta of diabetic rats [12]. That study displayed that the vasodilation effect of this plant in the presence of L-NAME was significantly reduced. Researchers believe that one of the mechanisms of the vasodilator effects of this plant aqueous extract is endothelium-dependent via increasing the synthesis or release of NO from endothelial cells. The extract probably exerts its effects on diabetic animals by collecting free radicals produced from the endothelium and thereby improving the function of NO [12]. Also, in the other studies, the underlying mechanism of action vasorelaxant effect of $A$. campestris $L$. aqueous extract was via calmodulin-NO-cGC-PKG pathway and activation of intracellular calcium mobilization into sarcoplasmic reticulum and via inhibition of Ltype $\mathrm{Ca} 2+$ channels and the activation of SERCA pumps of reticulum plasma $[10,14]$.

Many studies have shown that the therapeutic properties of medicinal plants are due to the presence of flavonoids which are polyphenols that exert their protective effects on the cardiovascular system through inhibition of platelet aggregation, free radical accumulation, and increased NO production [32]. Most of the flavonoids reduce the contractile response to phenylephrine in aortic rings, and their vasodilatation activity is inhibited in the presence of indomethacin [33], the same as the present results. The endothelium plays an important role in controlling vascular tonus through the release of vasodilator and vasoconstrictor factors [34]. Unlike the present study results, most of the effects of the flavonoids are only endotheliumdependent. They produce the vasodilatation effect through the production of $\mathrm{NO}$ from the endothelium and the increase in vasodilator prostaglandins (PGI2) [9,35-37]. While the effects of some of them are independent of the endothelium, they are triggered by the activation of calcium-dependent potassium channels and PCK inhibition $[38,39]$. The same as the present study results, some plant extracts such as Ginkgo biloba exert their vasodilator effect through both endothelium-dependently and independently [40].

\section{CONCLUSION}

According to the present results, since the vasodilator effect of the aqueous extract of $A$. annua with a concentration of $100 \mathrm{mg} / \mathrm{kg}$ was pronounced even after endothelium removal, it can be claimed that the vasorelaxant effects of the $A$. annua aqueous extract are both indirect (endothelium-dependent) and directly (endothelium- independent).

\section{ETHICAL APPROVAL}

The procedures involving the animals' use and care were approved by the ethics committee of Iran University of Medical Sciences, Tehran, Iran, and conducted in conformity with the National Institutes of Heals Guidelines.

\section{ACKNOWLEDGMENT}

This study was supported by a grant-in-aid from Iran University of Medical Sciences (Tehran, Iran). The authors gratefully appreciate the assistance of the personnel of Physiology Department and Cellular and Molecular Research Center of Iran University of Medical Sciences (Tehran, Iran).

\section{COMPETING INTERESTS}

Authors have declared that no competing interests exist.

\section{REFERENCES}

1. Omara AE, Kam A, Alqahtania A, Li KM, Razmovski-Naumovski V, Nammi S, Chan K, Roufogalis DB, Li QG. Herbal medicines and nutraceuticals for diabetic vascular complications: Mechanisms of action and bioactive phytochemicals. Current Pharmaceutical Design. 2010;16:37763807.

2. Ajiboye BO, Ojo OA, Adeyonu O, Imiere O, Oyinloye BE, Ogunmodede O. Ameliorative activity of ethanolic extract of Artocarpus heterophyllus stem bark on alloxan-induced diabetic rats. Advanced pharmaceutical bulletin. 2018;8:141.

3. Beisswenger PJ, Spiro RG. Human glomerular basement membrane: Chemical alteration in diabetes mellitus. Science. 1970;168:596-598.

4. Bohlen HG, Niggl BA. Arteriolar anatomical and functional abnormalities in juvenile mice with genetic or streptozotocininduced diabetes mellitus. Circulation research. 1979;45:390-396.

5. Hayoz D, Ziegler T, Brunner HR, Ruiz J. Diabetes mellitus and vascular lesions. Metabolism-Clinical and Experimental. 1998;47:16-19.

6. Durante $W$, Sen AK, Sunahara FA. Impairment of endothelium-dependent 
relaxation in aortae from spontaneously diabetic rats. British Journal of Pharmacology. 1988;94:463-468.

7. Pieper GM, Langenstroer $P$, Siebeneich W. Diabetic-induced endothelial dysfunction in rat aorta: Role of hydroxyl radicals. Cardiovascular Research. 1997;34:145156.

8. Mashour $\mathrm{NH}$, Lin $\mathrm{GI}$, Frishman $\mathrm{WH}$. Herbal medicine for the treatment of cardiovascular disease: Clinical considerations. Archives of internal Medicine. 1998;158:2225-2234.

9. Roghani M, Baluchnejadmojarad T, VaezMahdavi MR, Roghani-Dehkordi F. Mechanisms underlying quercetin-induced vasorelaxation in aorta of subchronic diabetic rats: An in vitro study. Vascular Pharmacology. 2004;42:31-35.

10. Liperoti R, Vetrano DL, Bernabei R, Onder G. Herbal medications in cardiovascular medicine. Journal of the American College of Cardiology. 2017;69:1188-99.

11. Ribnicky D, Poulev A, Watford M, Cefalu W, Raskin I. Antihyperglycemic activity of Tarralin $^{\mathrm{TM}}$, an ethanolic extract of Artemisia dracunculus L. Phytomedicine. 2006;13:550-557.

12. Baluchnejad Mojarad $T$, Roghani M, Sadeghi Mahali F. The role of nitric oxide and intracellular stores of calcium in the protective effect of artemisia annua aqueous extract on the contractile response of aortic rings to alpha 1adrenoceptor agonist in diabetic rats. Scientific Journal of Hamadan University of Medical Sciences. 2007;13:32-38.

13. Ben-Nasr $H$, Abderrahim MAB, Salama M, Ksouda K, Zeghal K-M. Potential phytotherapy use of Artemisia plants: insight for anti-hypertension. J Appl Pharm Sci. 2013;3:120-125.

14. Dib I, Tits $M$, Angenot $L$, Wauters JN, Assaidi A, Mekhfi $\mathrm{H}$, Aziz M, Bnouham M, Legssyer A, Frederich $M$, Ziyyat $A$. Antihypertensive and vasorelaxant effects of aqueous extract of Artemisia campestris L. from Eastern Morocco. Journal of Ethnopharmacology. 2017;206:224-35.

15. Dib I, Fauconnier ML, Sindic M, Belmekki $F$, Assaidi A, Berrabah M, Mekhfi H, Aziz $M$, Legssyer $A$, Bnouham $M$, Ziyyat $A$. Chemical composition, vasorelaxant, antioxidant and antiplatelet effects of essential oil of Artemisia campestris L. from Oriental Morocco. BMC comple-
Mentary and Alternative Medicine. 2017; 17(1):82.

16. Naoufel Z, Hebi M, Ajebli M, Michel BJ, Eddouks M. In vitro vasorelaxant effect of Artemisia herba alba Asso. in spontaneously hypertensive rats. Cardiovascular \& Hematological Agents in Medicinal Chemistry. Cardiovascular \& Hematological Agents in Medicinal Chemistry. 2016;14(3):190-6.

17. Esmaeili F, Sepehri G, MoshtaghiKashanian GR, Khaksari M, Salari N, Sepehri E. The effect of acute administration of Artemisia persia extracts on arterial blood pressure and heart rate in rats. American Journal of Applied Sciences. 2009;6:843.

18. Esmaeli F, Sepehri G, Joneidi $H$, Daneshvar S, Hasannejad M. Cardiac effects of subacute administration of Artemisia persia extract in normotensive and hypertensive rats. Ann. Biol. Res. 2012;3:34043-33409.

19. Aziz M, Karim A, EL Ouariachi E, Bouyanzer A, Amrani S, Mekhfi H, Ziyyat A, Melhaoui A, Bnouham M, Legssyer A. Relaxant effect of essential oil of Artemisia herba-alba Asso. on rodent jejunum contractions. Scientia Pharmaceutica. 2012;80:457.

20. Lee SJ, Chung HY, Lee IK, Oh SU, Yoo ID. Phenolics with inhibitory activity on mouse brain monoamine oxidase (MAO) from whole parts of Artemisia vulgaris $\mathrm{L}$ (Mugwort). Food Science and Biotechnology. 2000;9:179-182.

21. Helal EG, Aouf NA, Khattab AM, Zoair MA. Anti-diabetic effect of artemisia annua (kaysom) in alloxan-induced diabetic rats. Egyptian Journal of Hospital Medicine. 2014;57.

22. Baluchnejad Mojarad T, Roghani M, Zare N. Effect of subchronic administration of aqueous Artemisia annua extract on a1adrenoceptor agonist-induced contraction of isolated aorta in rat. Iranian Biomedical Journal. 2005;9:57-62.

23. Smith WL. Prostaglandin biosynthesis and its compartmentation in vascular smooth muscle and endothelial cells. Annual Review of Physiology. 1986;48:251-262.

24. Ingerman-Wojenski C, Silver M, Smith J, Macarak E. Bovine endothelial cells in culture produce thromboxane as well as prostacyclin. The Journal of Clinical Investigation. 1981;67:1292-1296. 
25. Alanko J, Riutta A, Vapaatalo $H$. Effects of catecholamines on eicosanoid synthesis with special reference to prostanoid/ leukotriene ratio. Free Radical Biology and Medicine. 1992;13:677-688.

26. Lamb VL, Schwartz AJ, Rohn WR, Kaiser L. Cyclooxygenase inhibitors depress norepinephrine constriction of rat abdominal, but not thoracic, aorta. European Journal of Pharmacology. 1994; 256:221-226.

27. Cameron N, Cotter M. Impaired contraction and relaxation in aorta from streptozotocindiabetic rats: Role of polyol pathway. Diabetologia. 1992;35:1011-1019.

28. Tesfamariam B, Jakubowski JA, Cohen RA. Contraction of diabetic rabbit aorta caused by endothelium-derived PGH2TxA2. American Journal of PhysiologyHeart and Circulatory Physiology. 1989; 257:H1327-H1333.

29. Roth D, Reibel D, Lefer A. Vascular responsiveness and eicosanoid production in diabetic rats. Diabetologia. 1983;24:372376.

30. Gerrard JM, Stuart MJ, Rao GH, Steffes MW, Mauer SM, Brown DM, White JG. Alteration in the balance of prostaglandin and thromboxane synthesis in diabetic rats. Translational Research. 1980;95:950958.

31. Pieper GM, Mei DA, Langenstroer $P$, O'Rourke ST. Bioassay of endotheliumderived relaxing factor in diabetic rat aorta. American Journal of Physiology-Heart and Circulatory Physiology. 1992;263:H676H680.

32. Formica J, Regelson W. Review of the biology of quercetin and related bioflavonoids. Food and chemical toxicology. 1995;33:1061-1080.

33. Ajay M, Gilani AUH, Mustafa MR. Effects of flavonoids on vascular smooth muscle of the isolated rat thoracic aorta. Life Sciences. 2003;74:603612.
34. Vanhoutte PM, Rubanyi GM, Miller VM, Houston DS. Modulation of vascular smooth muscle contraction by the endothelium. Annual Review of Physiology. 1986;48:307-320.

35. Paredes-Carbajal $\mathrm{M}$, Torres-Durán $\mathrm{P}$, Díaz-Zagoya J, Mascher D, JuárezOropeza M. Effects of the ethanolic extract of Spirulina maxima on endothelium dependent vasomotor responses of rat aortic rings. Journal of ethnopharmacology. 2001;75:37-44.

36. Rodríguez-Cruz $M$, Pérez-Ordaz $L$, Serrato-Barajas B, Juárez-Oropeza $M$, Mascher D, Paredes-Carbajal M. Endothelium-dependent effects of the ethanolic extract of the mistletoe Psittacanthus calyculatus on the vasomotor responses of rat aortic rings. Journal of Ethnopharmacology. 2003; 86:213-218.

37. Guerrero M, Puebla P, Carrón R, Martin M, Román LS. Quercetin 3, 7-dimethyl ether: a vasorelaxant flavonoid isolated from Croton schiedeanus Schlecht. Journal of Pharmacy and Pharmacology. 2002;54: 1373-1378.

38. Duarte J, Pérez FV, Utrilla $P$, Jiménez J, Tamargo J, Zarzuelo A. Vasodilatory effects of flavonoids in rat aortic smooth muscle. Structure-activity Relationships. General Pharmacology. 1993;24:857-862.

39. Pérez-Vizcaíno $F$, Ibarra $M$, Cogolludo AL, Duarte J, Zaragozá-Arnáez F, Moreno L, López-López G, Tamargo J. Endotheliumindependent vasodilator effects of the flavonoid quercetin and its methylated metabolites in rat conductance and resistance arteries. Journal of Pharmacology and Experimental Therapeutics. 2002; 302:66-72.

40. Nishida S, Satoh H. Mechanisms for the vasodilations induced by Ginkgo biloba extract and its main constituent, bilobalide, in rat aorta. Life Sciences. 2003;72:26592667.

(C) 2019 Sadeghimahalli et al.; This is an Open Access article distributed under the terms of the Creative Commons Attribution License (http://creativecommons.org/licenses/by/4.0), which permits unrestricted use, distribution, and reproduction in any medium, provided the original work is properly cited.

Peer-review history:

The peer review history for this paper can be accessed here: http://www.sdiarticle3.com/review-history/49243 